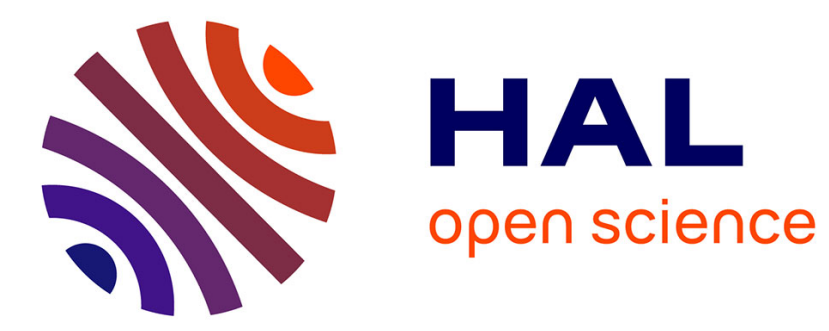

\title{
A new rationale for not picking low hanging fruits: The separation of ownership and control
}

Denis Claude, Mabel Tidball

\section{To cite this version:}

Denis Claude, Mabel Tidball. A new rationale for not picking low hanging fruits: The separation of ownership and control. 2019. hal-02316599

\section{HAL Id: hal-02316599 \\ https://hal.umontpellier.fr/hal-02316599}

Preprint submitted on 15 Oct 2019

HAL is a multi-disciplinary open access archive for the deposit and dissemination of scientific research documents, whether they are published or not. The documents may come from teaching and research institutions in France or abroad, or from public or private research centers.
L'archive ouverte pluridisciplinaire HAL, est destinée au dépôt et à la diffusion de documents scientifiques de niveau recherche, publiés ou non, émanant des établissements d'enseignement et de recherche français ou étrangers, des laboratoires publics ou privés.

\section{()ㅜ(1)}

Distributed under a Creative Commons Attribution - NoDerivatives| 4.0 International 


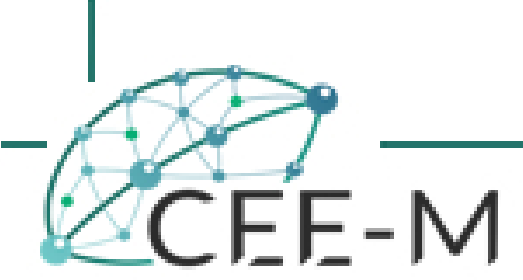

CENTER FOR ENVIRONMENTAL ECONOMICS - MONTPELLIER

A new rationale for not picking low hanging fruits:

The separation of ownership and control

\author{
Denis Claude \\ $\&$ \\ Mabel Tidball
}

CEE-M Working Paper 2019-21 


\title{
A new rationale for not picking low hanging fruits: The separation of ownership and control ${ }^{1}$
}

\author{
(a). LEDi, Université de Bourgogne-Franche Comté, Dijon, France \\ (b). CEE-M, Univ. Montpellier, CNRS, INRA, SupAgro, Montpellier, France
}

(a). LEDi, Université de Bourgogne-Franche Comté, Dijon, France

(b). CEE-M, Univ. Montpellier, CNRS, INRA, SupAgro, Montpellier, France

October 1, 2019

\footnotetext{
${ }^{1}$ Corresponding Author. Denis Claude, Laboratoire d'Economie de Dijon (LEDi), 2 boulevard Gabriel BP 2661, 21066 DIJON cedex. Email: denis.claude@u-bourgogne.fr

The authors acknowledge the financial support of the French Agence Nationale de la Recherche (ANR). Mabel Tidball received funding from the project GREEN-Econ (ANR-16-CE03-0005) and the LabEx Entreprendre (ANR-10-LABX-11-01). Denis Claude received funding from the project RILLM. The authors would like to thank the participants of the 18th International Symposium on Dynamic Games and Applications in July 2018 and the seminar participants at Center for Environmental Economics Montpellier and the University of Valladolid for helpfull discussions. The usual disclaimer applies.
} 
Abstract Recent attempts at explaining the energy-efficiency gap rely on considerations related to organizational and behavioral/cognitive failures. In this paper, we build on the strategic delegation literature to advance a complementary explanation. It is shown that strategic market interaction may encourage business owners to instill a bias against energy efficiency in managerial compensation contracts. Since managers respond to financial incentives, their decisions will reflect this bias, resulting in lack of investment. 
Keywords Energy efficiency, strategic delegation, behavioral bias, energy paradox 


\section{Introduction}

The optimization of production processes in combination with the acquisition of innovative energy efficiency solutions enable better energy management and performance. These energy efficiency improvements are beneficial in terms of reducing production costs, strengthening the competitive position of the firm and permiting the achievement of its social and environmental responsibility objectives. In light of this, firms should seize every opportunity to improve their energy efficiency. Yet, ample evidence show that even investments with low initial expenditures and quick returns do not materialize. This paradox - commonly referred to as "the energy efficiency gap" - prompted a large literature on the barriers that prevent firms from improving their energy efficiency. ${ }^{1}$

The energy-efficiency gap refers to the difference between the energy efficiency levels observed and those deemed privately optimal according to engineering studies (Jaffe \& Stavins, 1994). The actual extent of this gap is disputed (Sutherland, 1991). Some authors argue that engineering studies may overestimate it by ignoring hidden costs (Anderson \& Newell, 2004), including those arising from the imperfectly substitutability of technologies, transactions associated with the acquisition of new equipment and services, and firm heterogeneity. Indeed, energy efficiency solutions may have less satisfactory characteristics than standard equipment (e.g., color rendition under cool white Led illumination). Besides, their implementation may involve search, assessment and procurement costs. Lastly, adoption costs vary widely across firms depending on firm specific characteristics (Verhoef \& Nijkamp, 2003). Once hidden costs are accounted for, these skeptic authors argue, the remaining energy-efficiency gap, if any, is explained by market failures (Koomey \& Sanstad, 1994).

Sources of market failures are well documented (Fisher \& Rothkopf, 1989). Among these, information deficiencies play an important role in impeding investments (Howarth \& Anderson, 1993). Firms may simply lack accurate and dependable information about equipment attributes (e.g., energy-efficiency, running costs and reliability). Alternatively, information may be distributed asymmetrically across market participants allowing opportunistic behavior such as adverse selection, moral hazard and split incentives (Gillingham et al., 2009; Gerarden et al., 2017). For example, a company that is unable to confirm the energy-efficiency characteristics of a cost-effective equipment will balk at its price. Anticipating such reluctance from prospective customers, suppliers of energy saving technologies will market only cheap low-performance equipment.

Additionally, market failure may arise from externalities (Gerarden et al., 2017). The limited appropriability of returns on innovation activities discourages investment in energy-efficiency R\&D. Likewise, learning-by-doing spillovers incite firms to delay investment to benefit from the continuous flow of knowledge generated by early-adopters. Finally, the market for energy saving equipment may fail because of capital market failures, incomplete markets and irreversibilities. ${ }^{2}$

Market failure arguments may not be sufficient to close the energy-efficiency gap, however. Recent contributions suggest that organizational issues (DeCanio, 1993) combine with behavioral biases (Tientenberg, 2009; Allcott et al., 2014; Gillingham \& Palmer, 2014; Frederiks et al., $2015)$ to impede investments. Top management is made up of executives who differ in their training, skills, experience and goals. Firm behavior will reflect this complex set of idiosyncrasies (DeCanio, 1993; Cagno et al., 2013). Admittedly, short-term compensation contracts, rapid job rotation, and individual reputation building behaviors aiming at self-promotion convey

\footnotetext{
${ }^{1}$ For literature surveys, see Sorrell et al. 2004; Tientenberg 2009; Gillingham \& Palmer 2014; Gerarden et al. 2017.

${ }^{2}$ Or, to be more specific, liquidity constraints, risk and losses of future options.
} 
incentives that favor projects that offer a quick return on investment, thereby excluding investment in energy saving equipment (DeCanio, 1993; Sorrell et al., 2004).

Likewise, the scarce and selective managerial attention precludes the balancing of costs against benefits of investment. DeCanio (1993) notes that "[M]anagement attention and resources are scarce and must be concentrated on those areas deemed crucial to the survival of the firm (p. 910)". To economize on managerial attention, top management relies on simplified decision procedures aiming at satisfactory rather than optimal outcomes. For instance, as a way to reduce managerial discretion while saving on control costs, it may demand an unusually fast return on investment on smaller cost reduction projects, particularly those related to energy savings (Antle \& Eppen, 1985; DeCanio, 1993). The adoption of such simple heuristics might be perfectly rational in the face of uncertainty.

Selectivity suggests that managers focus their attention only on the most salient issues facing the firm (Frederiks et al., 2015; Gerarden et al., 2017; Cattaneo, 2019). It is reflected in the fact that decisions related to product management or strategic planning clearly enjoy greater standing than is accorded to energy cost savings. It further transpires from the better pay and greater prestige associated with corresponding executive positions. This difference in treatment may, in turn, discourage energy efficiency managers to further invest in human capital (DeCanio, 1993).

Inattention may be perfectly rational. Indeed, faced with prohibitive search and transaction costs and given limited managerial resources, firms may engage in 'rational inattention', a type of information processing characterized by self-imposed rationality constraints (Sallee, 2014). This could explain why, in actual practice, top managers seem to ignore (or heavily discount) energy cost savings and to focus exclusively on initial investment outlays. However, the differential treatment of benefits and costs may also result from the behavioral biases that top executives hold. Loss aversion -- the tendency to avoid losses over acquiring equivalent gains -- may provide part of the explanation. As noted by Cattaneo (2019), "it could be that investment costs are evaluated as a loss and are weighted more than gains". Other behavioral biases may explain why firms exhibit an inertia in adopting new technologies (Frederiks et al., 2015). Sunk costs effects may induce firms to retain obsolete equipment in an effort to recoup initial investment outlays. Besides, endowment effects may encourage firms to replace faulty (or tired) equipment by similar (or same) apparatus even though innovative cost-effective energy-efficient alternatives are available.

In this paper, we bridge the above three - economic, organizational and behavioral/cognitive perspectives. Our aim is to show that strategic market interaction may contribute to and even exacerbate behavioral and cognitive biases that are at the source of the energy-efficiency gap. The intuition for this result is based on the separation of ownership and control in modern corporations. We consider a strategic delegation game in which business owners decide whether or not to delegate executive decisions to a professional managers. As shown by Vickers (1985), Fershtman \& Judd (1987) and Sklivas (1987), delegation in Cournot markets has strategic value. By hiring a manager, the owner of a firm can credibly commit to pursue a goal that differs from maximizing profit. Indeed, the managerial incentives embedded in managerial compensation contracts make the deviation from profit maximization credible since managers respond to financial incentives. Delegation decisions and deviations from profit maximization may thus arise as an equilibrium behavior. ${ }^{3}$

In this game, we assume that production implies energy expenditures. Accordingly, when delegation actually occurs, managers are responsible for both production and energy conservation

\footnotetext{
${ }^{3}$ For a recent survey of the strategic delegation literature, see Kopel \& Pezzino (2018)
} 
decisions. The previous literature focused on deviations from profit maximization involving ingredients of sales revenue, market share or relative profit maximization. By contrast, here, we allow business owners to design compensation contracts that encourage managers to ignore part (or all) of energy costs. Such compensation contracts would result in an unequal weighting of energy costs savings and investment costs. It is shown that they are selected by business owners at the equilibrium of the strategic delegation game. Consequently, what is usually regarded as a cognitive bias - the unequal weighting of energy cost savings and investment costs- is sustained as an equilibrium behavior.

Our model is related to two previous contributions on managerial delegation decisions for polluting firms. In a Cournot duopoly with homogeneous goods and pollution emissions, BarcenaRuiz \& Garzon (2002) find that business owners favor revenue maximization at the expense of profits. Consequently, strategic delegation results in higher output levels and pollution emissions. The optimal environmental tax is then higher than that required to regulate a ownermanaged oligopoly. Pal (2012) generalizes this result to industries supplying differentiated products. In both models, stronger managerial incentives (i.e, a lower profit weight) lead managers to pay less attention to production costs with respect to sales revenues.

Our paper differs from these contributions along several important lines. We consider a different kind of deviation from profit maximization that has nothing to do with sales revenues, market share or relative profit objectives. Furthermore, we resort to strategic delegation arguments to explain why modern corporations may weight differently different type of costs - upfront investment outlays aimed at increasing energy conservation and recurring energy expenditures. In so doing, we show that strategic market interaction may contribute to and even exacerbate observed behavioral biases.

The paper is organized as follows. Section 2 describes the model. Section 3 solves the managerial subgame. Section 4 characterizes Subgame-Perfect Nash Equilibrium (SPNE) delegation decisions. The last section concludes.

\section{The Model}

We consider a duopoly market with two identical firms indexed by $i=1,2$. The two firms produce a homogeneous good $q$ and compete in quantities. Let $q_{i}$ denote firm $i$ 's output and $Q=\left(q_{1}+q_{2}\right)$ denote industry output. The inverse demand function is linear and given by $p(Q)=a-b Q$ with $a, b>0$. The production of the final good requires energy inputs. We assume that both firms buy energy inputs from the same energy retailer at a rate (i.e., fixed price), $r>0$. For sake of simplicity, we assume that firm i's demand for energy inputs is $e_{i}\left(q_{i}, \gamma_{i}\right)=$ $q_{i}-\gamma_{i}$ where $\gamma_{i} \geq 0$ denotes firm $i$ 's effort at energy conservation. Under this specification, absent of investment in energy efficiency, firms' production technologies are characterized by an unitary energy-output ratio; i.e., $e_{i}\left(q_{i}, 0\right)=q_{i}$. Also, energy conservation may be regarded as a substitute for energy consumption.

Obviously, a reduction in energy input use - or an increase in energy conservation- is highly desirable from the firm's perspective. However, further increases in energy conservation require increasingly experienced staff and increasingly specialized capital. Hence, increases in energy conservation come at an increasing cost. To reduce its overall energy consumption by $\gamma_{i}$ units, we suppose that firm $i$ incurs a cost equal to $K_{i}\left(\gamma_{i}\right)=\frac{k}{2} \gamma_{i}^{2}$.

Firm $i$ 's energy bill writes as $B\left(q_{i}, \gamma_{i}, r\right)=r\left(q_{i}-\gamma_{i}\right)$. We restrict our attention to investments in energy efficiency. In particular, we assume away the possibility for firms to sell excess energy back to the energy retailer. This implies that $\gamma_{i} \leq q_{i}$ so that Firm $i$ 's energy bill is always non- 
negative. Also, we assume that consumers (maximal) willingness to pay for the good exceeds the price of energy; i.e., $a>r$. Firm owner-managers seek to maximize profits, which are given by: ${ }^{4}$

$$
\pi_{i}=(a-b Q) q_{i}-r\left(q_{i}-\gamma_{i}\right)-\frac{k}{2} \gamma_{i}^{2}, \quad i=1,2 .
$$

However, if profitable, owner-managers may choose to divorce ownership from control . In other words, each owner $i$ may delegate day-to-day production decisions to a manager. We assume that managers respond to financial incentives and, accordingly, seek to maximize their compensation. By appropriately designing the managerial compensation contract, each owner is able to direct managers to pursue an objective that differ from profit maximization. Since managerial compensation in publicly traded companies is common knowledge, this strategic move will convey to rival firms the credible commitment to a deviation from (pure) profit-maximization.

Managerial compensation is assumed to depend on managerial performance. Specifically, we assume a two-part compensation scheme $w_{i}=w_{i}^{F}+w_{i}^{V} M_{i}$ consisting of a base salary $w_{i}^{F} \geq 0$ and a commission on performance $w_{i}^{V} M_{i}$, where $w_{i}^{V}>0$ is the rate at which the performance measured by $M_{i}$ is rewarded. Given this scheme, each manager $i$ will maximize $M_{i}$ in order to maximize its compensation $w_{i}$.

To answer the question whether discounting energy costs could be rational, we consider a class of performance measures defined with respect to $\delta_{i}$ by:

$$
M_{i}\left(\delta_{i}\right)=(a-b Q) q_{i}-\delta_{i} r\left(q_{i}-\gamma_{i}\right)-\frac{k}{2} \gamma_{i}^{2}, \quad \text { for all } \delta_{i} \in[0,1] \text { and } i=1,2 .
$$

By adjusting the value of $\delta_{i}$, the owner of Firm $i$ generates a continuum of managerial incentives that range from pure-profit maximization $\left(\delta_{i}=1\right)$ to a complete disregard for energy costs $\left(\delta_{i}=0\right)$. One important remark must be made here. Unless $\delta_{i}$ is set to one, the above-defined class of performance measure does not weight equally the different types of costs involved in production. While expenditures aimed at improving energy efficiency are fully accounted for, energy input costs are at least partially ignored. This is consistent with empirical evidence which highlight that economic agents (consumers or firms) display a tendency to weight differently savings and costs. Our purpose here is to show that such a bias may sometimes be rational rather than linked to defeating cognitive illusions. To the best of our knowledge, no other paper in the strategic delegation literature includes such a differential treatment of the different types of costs that the firm faces.

The timing of the game is as follows (See, Figure 1). At the first stage, both firm owners independently and simultaneously decide whether to hire a manager - and if so, design the managerial compensation contract. To state it differently, both owners set the rate at which input energy costs will be discounted so as to maximize profits. At the second stage, firm managers respond to incentives by independently and simultaneously setting their production and energy conservation levels so as to maximize managerial compensation. The game is solved by backward induction for a Subgame-Perfect Nash-Equilibrium (SPNE). Hence the next section is devoted to the analysis of the managerial subgame.

\section{Managerial production and investment decisions}

At stage two, the managerial incentives embedded in compensation contracts $\left(\delta_{1}, \delta_{2}\right)$ have become public knowledge. Given those incentives, each manager $i$ simultaneously and indepen-

\footnotetext{
${ }^{4}$ Since managerial compensation is intended to secure the participation of managers, it will be equal to their respective (exogeneouly defined) reservation incomes. Consequently, from an owner's perspective, maximizing profit net of compensation is the same as maximizing profit. For more on this point, see Kopel \& Pezzino (2018).
} 


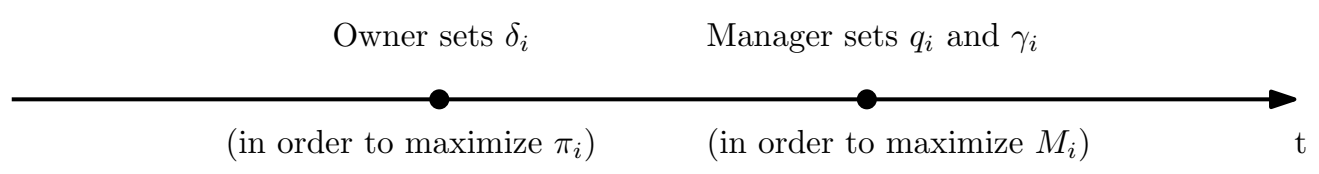

Fig. 1: Timing of the game

dently sets its output $q_{i}$ and energy conservation effort $\gamma_{i}$ to maximize own compensation, taking as given the choices of the manager of the rival firm. A Nash equilibrium of the managerial subgame is a profile of strategies $\left(q_{1}^{\star}, \gamma_{1}^{\star}, q_{2}^{\star}, \gamma_{2}^{\star}\right)$ such that $\left(q_{i}^{\star}, \gamma_{i}^{\star}\right)$ solves the problem of managerial compensation maximization faced by Manager $i$ for all $i=1,2:^{5}$

$$
\begin{gathered}
\max _{q_{i}, \gamma_{i}} M_{i}=(a-b Q) q_{i}-\delta_{i} r\left(q_{i}-\gamma_{i}\right)-\frac{k}{2} \gamma_{i}^{2}, \\
\text { s.t.: } \quad \frac{a}{b}-q_{i} \geq 0, \quad \gamma_{i} \geq 0, \quad q_{i}-\gamma_{i} \geq 0 .
\end{gathered}
$$

The Lagrangean associated with Problem 1 is:

$$
\mathscr{L}_{i}=(a-b Q) q_{i}-\delta_{i} r\left(q_{i}-\gamma_{i}\right)-\frac{k}{2} \gamma_{i}^{2}+\lambda_{i}\left(\frac{a}{b}-q_{i}\right)+\mu_{i}\left(q_{i}-\gamma_{i}\right)+v_{i}\left(\gamma_{i}\right) .
$$

The Karush-Kuhn-Tucker (KKT) conditions yield:

$$
\begin{array}{llrl} 
& & \frac{\partial \mathscr{L}_{i}}{\partial q_{i}}=a-2 b q_{i}-b q_{j}-\delta_{i} r-\lambda_{i}+\mu_{i}=0, \\
\gamma_{i} \geq 0, & \frac{\partial \mathscr{L}_{i}}{\partial \gamma_{i}}=\delta_{i} r-k \gamma_{i}-\mu_{i} \leq 0, & -\gamma_{i}\left(\delta_{i} r-k \gamma_{i}-\mu_{i}\right)=0, \\
\lambda_{i} \geq 0, & \frac{\partial \mathscr{L}_{i}}{\partial \lambda_{i}}=\frac{a}{b}-q_{i} \geq 0, & \lambda_{i} \frac{\partial \mathscr{L}_{i}}{\partial \lambda_{i}}=\lambda_{i}\left(\frac{a}{b}-q_{i}\right)=0, \\
\mu_{i} \geq 0, & \frac{\partial \mathscr{L}_{i}}{\partial \mu_{i}}=q_{i}-\gamma_{i} \geq 0, & \mu_{i} \frac{\partial \mathscr{L}_{i}}{\partial \mu_{i}}=\mu_{i}\left(q_{i}-\gamma_{i}\right)=0 .
\end{array}
$$

Due to the concavity of $M_{i}$ and the linearity of the constraints the above necessary conditions are also sufficient for optimality.

The KKT conditions delineate up to four regions of the $\left(\delta_{1}, \delta_{2}\right)$ plane, as illustrated in Figure $2 \mathrm{a}$. For the time being, let us assume that these four regions actually exist. Let the lines

$$
\ell_{j}\left(\delta_{i}\right)=\frac{k\left(a+r \delta_{i}\right)}{r(3 b+2 k)}, \quad \ell_{i}\left(\delta_{i}\right)=\left(2+\frac{3 b}{k}\right) \delta_{i}-\frac{a}{r},
$$

denote the boundaries that delimit the region in which an interior Nash equilibrium obtains. This region, which is labeled I in Figure 2a, may be formally defined as:

$$
\text { Region I }=\left\{\left(\delta_{i}, \delta_{j}\right) \mid 0 \leq \delta_{i}<\ell_{i}^{-1}\left(\delta_{j}\right), 0 \leq \delta_{j}<\ell_{j}\left(\delta_{i}\right)\right\}
$$

The lines $l_{j}\left(\delta_{i}\right)$ and $l_{i}\left(\delta_{i}\right)$ intersect at the point $(\tilde{\delta}, \tilde{\delta})$ in the coordinate plane, where

$$
\tilde{\delta}=\frac{a k}{r(3 b+k)}
$$

\footnotetext{
5 The assumption that $\frac{a}{b}-q_{i} \geq 0$ ensures that firm $i$ 's strategy set $(i=1,2)$ is compact. This condition has obvious economic meaning. It says that manager $i$ would not select a quantity leading to a negative price when firm $i$ is the only active firm in the market.
} 

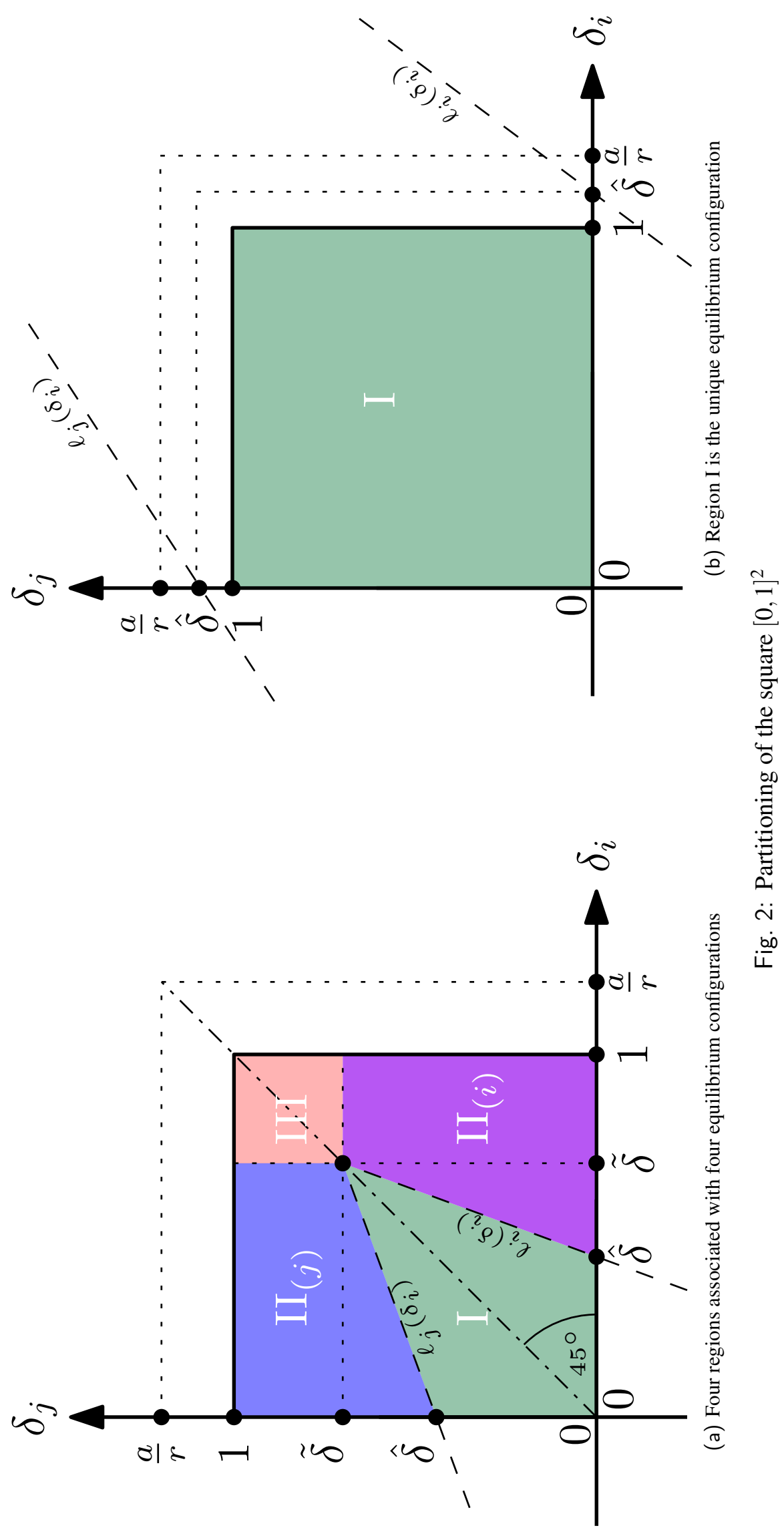
This point generates two other boundaries of interest: $\delta_{i}=\tilde{\delta}, i=1,2$. Consider the two trapezoid areas labeled $\mathrm{II}_{(k)}, k=1,2$, in Figure $2 \mathrm{a}$. Region $\mathrm{II}_{(i)}$ is delimited by $\ell_{i}\left(\delta_{i}\right)$ and $\delta_{j}=\tilde{\delta}$. It describes the set of all pairs of managerial incentives $\left(\delta_{1}, \delta_{2}\right)$ that would induce Manager $i$ to stop buying energy; i.e., to set $\gamma_{i}=q_{i}$. Conversely, region $\mathrm{II}_{(j)}$, which is delimited by $\ell_{j}\left(\delta_{i}\right)$ and $\delta_{i}=\tilde{\delta}$, describes all $\left(\delta_{1}, \delta_{2}\right)$-pairs that would induce Manager $j$ to set $\gamma_{j}=q_{j}$. These two regions may be respectively defined as:

$$
\begin{aligned}
& \text { Region II(i) }=\left\{\left(\delta_{i}, \delta_{j}\right) \mid \ell_{i}^{-1}\left(\delta_{j}\right) \leq \delta_{i} \leq 1,0 \leq \delta_{j}<\tilde{\delta}\right\}, \\
& \text { Region II(j) }=\left\{\left(\delta_{i}, \delta_{j}\right) \mid \ell_{j}\left(\delta_{i}\right) \leq \delta_{j} \leq 1,0 \leq \delta_{i}<\tilde{\delta}\right\} .
\end{aligned}
$$

A last region, which may be defined as

$$
\text { Region III }=\left\{\left(\delta_{i}, \delta_{j}\right) \mid \delta_{i} \geq \hat{\delta}, \delta_{j} \geq \hat{\delta}\right\}
$$

describes the set of all $\left(\delta_{1}, \delta_{2}\right)$-pairs that would induce both managers to stop buying energy $\left(\gamma_{i}=q_{i}, i=1,2\right)$.

Depending on parameter values, all four regions may not exist. We proceed by characterizing conditions under which only interior Nash equilibria obtains.

Let

$$
\hat{\delta}=\frac{a k}{r(3 b+2 k)} .
$$

From Figure $2 \mathrm{a}$, observe that Region I fully encompasses the subset $[0,1]^{2}$ of the coordinate plane whenever $\hat{\delta}>1$. This will be the case if the price of energy is sufficiently low; Namely, if

$$
r<r_{1}:=\frac{a k}{(3 b+2 k)} \text {. }
$$

Now, if $\hat{\delta} \leq 1$ but $\tilde{\delta}>1$, or equivalently, if

$$
r_{1}:=\frac{a k}{(3 b+2 k)} \leq r<\frac{a k}{(3 b+k)}:=r_{2},
$$

\begin{tabular}{|c|c|c|c|c|}
\hline & & & & \\
\hline & I & $\mathrm{II}_{(i)}$ & $\mathrm{II}_{(j)}$ & III \\
\hline 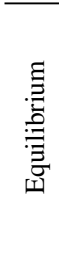 & $\begin{array}{c}q_{i}^{I}=\frac{a-r\left(2 \delta_{i}-\delta_{j}\right)}{3 b} \\
q_{j}^{I}=\frac{a-r\left(2 \delta_{j}-\delta_{i}\right)}{3 b} \\
\gamma_{i}^{I}=\frac{r \delta_{i}}{k} \\
\gamma_{j}^{I}=\frac{r \delta_{j}}{k} \\
p^{I}=\frac{\left(a+r\left(\delta_{i}+\delta_{j}\right)\right)}{3}\end{array}$ & 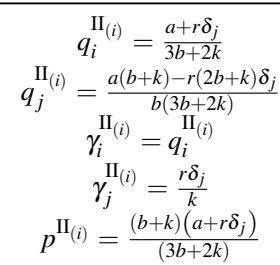 & 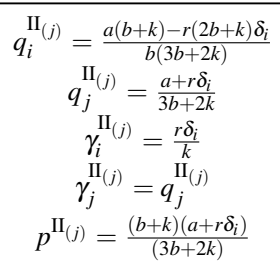 & $\begin{array}{c}q_{i}^{\mathrm{III}}=\gamma_{i}^{\mathrm{III}}=\frac{a}{(3 b+k)} \\
i=1,2 . \\
p^{\mathrm{III}}=\frac{a(b+k)}{3 b+k}\end{array}$ \\
\hline
\end{tabular}

then Region III does not exist. Finally, if the price of energy is sufficiently high $\left(r \geq r_{2}\right)$, the KKT conditions partition the $[0,1]^{2}$ into four regions. ${ }^{6}$

Equilibrium configurations associated with these four regions are given in Table 1.

Tab. 1: The four equilibrium configurations

Having completed the analysis of the managerial subgame, we can now turn to the analysis of strategic delegation decisions.

\footnotetext{
${ }^{6}$ If $r=r_{2}$ then Region III reduces to the point $(1,1)$.
} 


\section{Delegation and design of managerial compensation contracts}

At stage 1, each firm owner decides simultaneously and independently whether to hire a manager, and - if so, sets managerial incentives so as to maximize its profit. As noted above, the KKT conditions delineate $u p$ to four different regions, each associated with a different equilibrium configuration. Given this partitioning, the profit function of each owner is defined by a piecewise function. Profit maximization then yields piecewise reaction correspondences. Before solving the whole game, we shall consider a reduced model obtained by assuming that the price of energy is low enough to ensure that Region I encompasses the square $[0,1]^{2}$.

\subsection{Low energy price:}

Let us recall from section 3 that $r<r_{1}$ implies $[0,1]^{2} \subseteq$ Region I. In other words, for any pair of managerial incentives $\left(\delta_{i}, \delta_{j}\right)$ set by firm owners, the equilibrium of the managerial subgame is unique and given by $\left(q_{i}^{I}, \gamma_{i}^{I}, q_{j}^{I}, \gamma_{i}^{I}\right)$. The profit of Owner $i$ evaluated at the equilibrium is defined by:

$$
\pi_{i}^{I}\left(\delta_{i}, \delta_{j}\right):=\pi_{i}\left(q_{i}^{I}\left(\delta_{i}, \delta_{j}\right), \gamma_{i}^{I}\left(\delta_{i}, \delta_{j}\right), q_{j}^{I}\left(\delta_{i}, \delta_{j}\right), \gamma_{i}^{I}\left(\delta_{i}, \delta_{j}\right)\right), \quad i(\neq j)=1,2 .
$$

A pair of managerial incentives $\left(\delta_{i}^{I}, \delta_{j}^{I}\right)$ is a Subgame-Perfect Nash-Equilibrium of the game among owners if, and only if, $\delta_{i}^{I} \in \arg \max _{\delta_{i} \in[0,1]} \pi_{i}^{I}\left(\delta_{i}, \delta_{j}^{I}\right)$ for $i, j(i \neq j)=1,2$. The corresponding first-order conditions are:

$$
\frac{\partial \pi_{i}^{I}\left(\delta_{i}, \delta_{j}\right)}{\partial \delta_{i}}=0, \quad a k r+r^{2}\left(9 b\left(\delta_{i}-1\right)+\left(4 \delta_{i}+\delta_{j}-6\right) k\right)=0,
$$

for $i, j(i \neq j)=1,2$. Then, Manager $i$ 's reaction function is given by :

$$
\delta_{i} \equiv \phi_{i}\left(\delta_{j}\right)=\frac{3 r(3 b+2 k)-a k}{(9 b+4 k) r}-\frac{k}{(9 b+4 k)} \delta_{j}, \quad i(\neq j)=1,2 .
$$

Since the Hessian matrix is negative definite, $\pi_{i}^{I}\left(\delta_{i}, \delta_{j}\right)$ is strictly concave, and the above necessary conditions are also sufficient for optimality. Solving the system (18) yields

$$
\delta_{i}^{\star}=1-\frac{k(a-r)}{(9 b+5 k) r}, \quad i=1,2 .
$$

Recall our assumption that $\delta_{i} \in[0,1]$. Observe that $\delta_{i}^{\star}<1$. However, note that $\delta_{i}^{\star}<0$ for

$$
0<r<r_{0}:=\frac{a k}{3(3 b+2 k)} \text {. }
$$

In this case, given the positivity constraint on $\delta_{i}$, the best Owner $i$ can do is set $\delta_{i}^{I}=0$. We have the following proposition.

Proposition 1. If the energy rate $r$ is relatively low, the two-stage game admits a unique Subgame-Perfect Nash Equilibrium. At this equilibrium, business owners provide managers with incentives to discount energy costs. Equilibrium discount factors are given by

$$
\delta_{i}^{I}= \begin{cases}0 & \text { if } 0<r \leq r_{0}, \\ \delta_{i}^{\star}, & \text { if } r_{0}<r \leq r_{1},\end{cases}
$$

for $i=1,2$.

From the above proposition it follows that business owners may require management to wholly ignore energy expenditures if the energy rate $r$ is low enough. 


\subsection{Moderate-to-high energy price}

When energy becomes expensive, the question arises as to whether the pair of managerial incentives described by Equation (20) remains a Subgame-Perfect Nash Equilibrium of the game. This will be the case if the strategic pair $\left(\delta_{i}^{\star}, \delta_{j}^{\star}\right)$ satisfies two conditions: (i) it is an element of Region I for $r>r_{1}$ and (ii) it is immune from unilateral deviations. To begin with, let us check the former condition. Observe that the point $\left(\delta_{i}^{\star}, \delta_{j}^{\star}\right)$ is located along the $45^{\circ}$ line for all $r>r_{1}$. Hence, it is an element of Region I provided that $\delta_{i}^{\star}=\delta_{j}^{\star}<\tilde{\delta}$ or, equivalently, that

$$
r<r_{3}:=\frac{2 a k(2 b+k)}{(3 b+k)(3 b+2 k)} .
$$

We proceed by checking that the strategic pair $\left(\delta_{i}^{\star}, \delta_{j}^{\star}\right)$ is immune from unilateral deviations. Assume that Owner $j$ contemplates deviating from $\delta_{j}^{\star}$ to any $\delta_{j}^{d} \in\left[\ell_{j}\left(\delta_{i}^{\star}\right), 1\right]$. The resulting change in Owner $j$ profit is given by :

$$
\begin{aligned}
\pi_{j}^{\mathrm{II}(j)}\left(\delta_{i}^{\star}, \delta_{j}^{d}\right)-\pi_{j}^{\mathrm{I}}\left(\delta_{i}^{\star}, \delta_{j}^{\star}\right) & =\pi_{j}^{\mathrm{II}_{(j)}}\left(\delta_{i}^{\star}\right)-\pi_{j}^{\mathrm{I}}\left(\delta_{i}^{\star}, \delta_{j}^{\star}\right), \\
& =-\frac{(9 b+4 k)(r(3 b+k)(3 b+2 k)-2 a k(2 b+k))^{2}}{2 b k(3 b+2 k)^{2}(9 b+5 k)^{2}}<0 .
\end{aligned}
$$

Therefore, Owner $\mathrm{j}$ has no profitable deviation, and neither does Owner $i$ by symmetry. We can state the following proposition.

Proposition 2. Unless the price of energy becomes prohibitive $\left(r>r_{3}\right)$, the combination of managerial incentives $\left(\delta_{i}^{\star}, \delta_{j}^{\star}\right)$ is a Subgame-Perfect Nash-Equilibrium outcome.

The question now is whether the game has equilibria in other parts of the coordinate space. The following lemma narrows down the search.

Lemma 1. Let $\left(\delta_{i}^{c_{k}}, \delta_{j}^{c_{k}}\right)$ be any pair of managerial incentives from Region $I_{(k)}, k=1,2$. Then, $\left(\delta_{i}^{c_{k}}, \delta_{j}^{c_{k}}\right)$ cannot be a Subgame-Perfect Nash-Equilibrium.

Proof. See Appendix A.

As a consequence of Lemma 1, we need only consider Region III. To simplify exposition, in the remainder of this paper, any equilibrium solution in Region I (resp., III) is referred to as an interior (resp., a corner) equilibrium. Note that Region III exists if, and only if, $r>r_{2}$. Furthermore, note that there is an overlap between the interval of energy prices which ensures the existence of an interior solution $\left(0<r<r_{3}\right)$, and that which guarantees that Region III is not empty $\left(r_{2} \leq r<a\right)$. For energy prices in the interval $\left[r_{2}, r_{3}\right)$, interior and corner equilibria may coexist leading to potential coordination problems. The existence of a corner equilibrium is assured for an energy price greater or equal to

$$
r_{4}=\frac{a k(2 b+k)^{2}}{(b+k)(3 b+k)^{2}}
$$

as detailed in the following proposition.

Proposition 3. If $r \geq r_{4}$, then any pair $\left(\delta_{i}, \delta_{j}\right) \in$ Region III is a Subgame-Perfect Nash Equilibrium.

Proof. See Appendix B.

The next section discusses our findings. 


\subsection{Interpretation of the results}

Let us combine the results from the previous two sections to describe how the equilibrium behavior of business owners is affected by the price of energy. Reference to Figure 3 will be of assistance for the reader here. When the price of energy is very low $\left(r \in\left(0, r_{0}\right]\right)$, competition concerns trump energy saving concerns. Indeed, the increase in sales revenues more than compensates for the increased expenditures in energy inputs. Thus, business owners strategically take advantage of delegation to commit their managers to be more aggressive on the product market. This is done by designing compensation contracts so as to encourage managers to ignore energy costs in their everyday production and investment decisions. Compensation contracts then require that managerial performance be evaluated and rewarded solely in terms of sales revenue net of capital expenditures - thus explicitly excluding energy cost savings. In that event, top managers regard investment as both costly and irrelevant because it does not contribute to their compensation. Investment in energy efficiency is then effectively deterred.

Apart from this specific case, business owners have to strike a balance between competitive and energy saving concerns. Accordingly, for $r>r_{0}$, they set non-zero discount factors. From Equation 20, we have the following comparative statics result:

$$
\frac{\partial \delta_{i}^{\star}}{\partial r}=\frac{a k}{(9 b+5 k) r^{2}}>0, \quad \text { for } r_{0}<r<r_{3} .
$$

Namely, the equilibrium weight $\delta_{i}^{\star}$ is monotonically increasing on $\left(r_{0}, r_{3}\right)$ implying that an increase in the price of energy justifies greater attention to energy costs. However, there are two caveats here. First, note that $\delta_{i}^{\star}$ is bounded from above by:

$$
\delta_{\max }^{\star}=\lim _{r \rightarrow r_{3}} \delta_{i}^{\star}(r)=1-\frac{b}{2(2 b+k)} .
$$

This upper-bound originates from the fact that values of $\delta_{i}$ larger than $\tilde{\delta}$ are associated with a different equilibrium configuration in the managerial subgame (i.e., that which corresponds to Region III). Accordingly, small changes in the energy rate around $r=r_{3}$ may lead to jumps in equilibrium discount rate for there are multiple Nash equilibria on which business owners may coordinate.

When the price of energy becomes cost-prohibitive $\left(r>r_{3}\right)$, energy savings become the dominant concern for business owners. Indeed, the increase in sales revenues no longer compensates for increased expenditures in energy inputs. Consequently, at the equilibrium, the two business owners choose relatively high discount factor $\left(\delta_{i}>\tilde{\delta}\right)$. Thereby, they encourage managers to close the energy-efficiency gap by setting $q_{i}=\gamma_{i}$. In that case, the energy costs borne by the two firms are zero and, thus, changes in the value of $\delta$ restricted to the interval $[\tilde{\delta}, 1]$ alter neither managerial production and investment decisions nor business owners profits. Correspondingly, the set of Subgame Perfect Nash Equilibrium discount rates is given by $[\tilde{\delta}, 1]^{2}$. Besides, profit maximization is a natural focal point because business owners are indifferent between all their equilibrium strategies including $\delta_{i}=1$. Under the circumstances, business owners may successfully coordinate their hiring and compensation decisions so that delegation does not occur and the industry remains owner-managed. The differents components of cost will then be weighted the same at the managerial level.

Second, observe however that this set of corner equilibria emerges for relatively high - but not necessarily cost-prohibitive - energy prices $\left(r \geq r_{4}\right)$. Hence, the two equilibrium configurations ('interior' and 'corner') coexist provided that $r \in\left[r_{4}, r_{3}\right)$. Furthermore, there is a threshold 


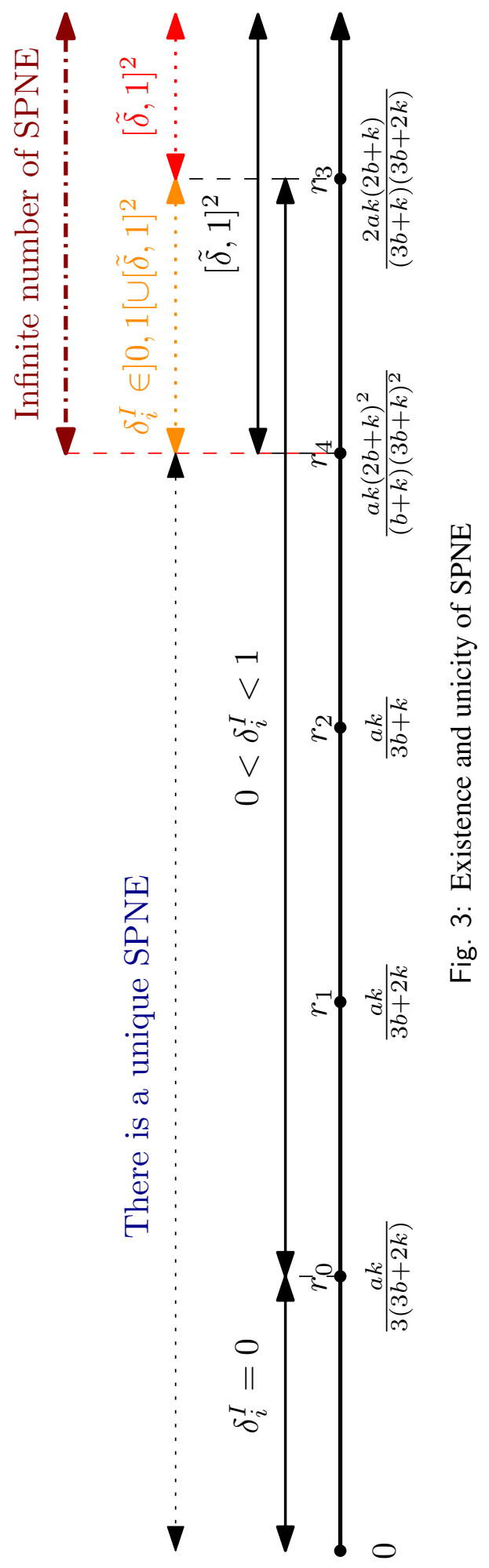


value $^{7}$ for the energy rate below (resp., above) which the 'interior' equilibrium Pareto dominates (resp., is Pareto dominated by) 'corner' equilibria. In that case, business owners face a coordination game. Here again, profit maximization provides a focal point for business owners. However, efficiency arguments may support delegation decisions.

\section{Conclusion}

Empirical research highlight that firms exhibit behavioral biases in their energy efficiency investment decisions. It appears that managers attribute less weight in their decision-making to potentially achievable savings than to the initial investment cost. Uncertainty and irreversibility of investment fail to explain this difference in treatment between the various components of the firm's profit function. Recent explanations have suggested the possibility that behavioral biases such as loss aversion or sunk cost effects may explain why profit maximizing investments in energy efficiency are sometimes not undertaken.

In this paper, we proposed a complementary explanation based on strategic delegation theory. It was shown that imperfect competition may encourage business owners to manipulate the terms of managerial compensation contracts to reward investment behaviors exhibiting a bias against energy efficiency. In this case, the performance measure used to assess managerial effectiveness and compensation attributes more weight to investment costs than to energy related cost savings. The rate at which energy costs are discounted is shown to depend on the price of energy. When the price of energy is low, competitive concerns dwarf energy cost concerns. Consequently, business owners encourage managers to ignore energy expenditures. However, as the price of energy increases, energy costs weight more in decision-making. Accordingly, owners encourage managers to be increasingly attentive not to waste energy. Finally, in scenarios where the price of energy is prohibitive, there are multiple rational behaviors and coordination issues arise.

The explanation we propose is not intended to replace existing organizational and behavioral explanations. Rather, it aims to emphasize that these accounts can be reinforced by strategic considerations. Contrary to a widely held belief, market competition may play a role - albeit limited - in explaining the maintenance of the energy-efficiency gap.

An important managerial insight from our analysis is that managerial compensation contracts should reflect energy market conditions. When energy prices are high, managers should be encouraged to monitor carefully energy costs and invest in energy efficiency. Conversely, when energy prices are low, they should be encouraged to focus on competitive issues. Modeling uncertainty regarding energy prices is a possible avenue for extension of the results of the present contribution.

\section{References}

Allcott, Hunt, Mullainathan, Sendhil, \& Taubinsky, Dmitry. 2014. Energy policy with externalities and internalities. Journal of Public Economics, 112, 72 - 88.

Anderson, Soren, \& Newell, Richard. 2004. Information programs for technology adoption: the case of energy-efficiency audits. Resource and Energy Economics, 26(1), 27-50.

Antle, Rick, \& Eppen, Gary D. 1985. Capital Rationing and Organizational Slack in Capital Budgeting. Management Science, 31(2), 163-174.

\footnotetext{
${ }^{7}$ We omit the expression of this threshold because it is very lengthy
} 
Barcena-Ruiz, Juan Carlos, \& Garzon, Maria Begona. 2002. Environmental taxes and strategic delegation. Spanish Economic Review, 4(4), 301-310.

Cagno, E., Worrell, E., Trianni, A., \& Pugliese, G. 2013. A novel approach for barriers to industrial energy efficiency. Renewable and Sustainable Energy Reviews, 19, 290 - 308.

Cattaneo, Cristina. 2019. Internal and External barriers to energy efficiency: which role for policy interventions. Energy efficiency, 12, 1293-1311.

DeCanio, Stephen J. 1993. Barriers within firms to energy-efficient investments. Energy Policy, 21(9), 906 - 914.

Fershtman, Chaim, \& Judd, Kenneth L. 1987. Equilibrium incentives in oligopoly. The American Economic Review, 77(5), 927-940.

Fisher, Anthony C., \& Rothkopf, Michael H. 1989. Market failure and energy policy: A rationale for selective conservation. Energy Policy, 17(4), 397-406.

Frederiks, Elisha R., Stenner, Karen, \& Hobman, Elizabeth V. 2015. Household energy use: Applying behavioural economics to understand consumer decision-making and behaviour. Renewable and Sustainable Energy Reviews, 41(C), 1385-1394.

Gerarden, Todd D., Newell, Richard G., \& Stavins, Robert N. 2017. Assessing the EnergyEfficiency Gap. Journal of Economic Literature, 55(4), 1486-1525.

Gillingham, Kenneth, \& Palmer, Karen. 2014. Bridging the Energy Efficiency Gap: Policy Insights from Economic Theory and Empirical Evidence. Review of Environmental Economics and Policy, 8(1), 18-38.

Gillingham, Kenneth, Newell, Richard G, \& Palmer, Karen. 2009. Energy efficiency economics and policy. Annual Review of Resource Economics, 1(1), 597-620.

Howarth, Richard B., \& Anderson, Bo. 1993. Market barriers to energy efficiency. Energy policy, Oct., 262-272.

Jaffe, Adam B., \& Stavins, Robert N. 1994. The energy-efficiency gap: What does it mean? Energy Policy, 22(10), $804-810$.

Koomey, Jonathan G., \& Sanstad, Alan H. 1994. Technical evidence for assessing the performance of markets affecting energy efficiency. Energy Policy, 22(10), 826-832.

Kopel, Michael, \& Pezzino, Mario. 2018. Strategic Delegation in Oligopoly. Chap. 10, pages 248-285 of: Corchon, Luis, \& Marini, Marco (eds), Handbook of Game Theory and Industrial Organization, vol. II. Edward Elgar.

Pal, Rupayan. 2012. Delegation and Emission tax in a Differentiated Oligopoly. The Manchester School, 80(6), 650-670.

Sallee, James M. 2014. Rational Inattention and Energy Efficiency. The Journal of Law and Economics, 57(3), 781-820.

Sklivas, Steven D. 1987. The strategic choice of managerial incentives. The RAND Journal of Economics, 18(3), 452-458. 
Sorrell, Steve, O'Malley, Eoin, Schleich, Joachim, \& Scott, Sue (eds). 2004. The economics of energy efficiency: barriers to cost-effective investment. Cheltenham, Uk; Northampton, MA, USA: Edward Elgar.

Sutherland, Ronald J. 1991. Market Barriers to Energy-Efficiency Investments. The Energy Journal, 12(3), 15-34.

Tientenberg, Tom. 2009. Energy Efficiency Policy: Pipe Dream or Pipeline to the Future? . Review of Environmental Economics and Policy, 3(2), 304-320.

Verhoef, Erik T., \& Nijkamp, Peter. 2003. The adoption of energy-efficiency enhancing technologies: Market performance and policy strategies in case of heterogeneous firms. Economic Modelling, 20(4), 839-871.

Vickers, John. 1985. Delegation and the Theory of the Firm. The Economic Journal, 95(Supplement: Conference Papers), 138-147.

\section{Appendices}

\section{A Proof of Lemma 1}

Let $\mathrm{BR}_{i}(x)$ denote the set of decisions that are best-responses to a decision $x$ for player $i, i=1,2$. Let $\left(\delta_{i}^{\mathrm{c}_{k}}, \delta_{j}^{\mathrm{c}_{k}}\right)$ be any pair of managerial incentives from Region $\mathrm{II}_{(k)}, k=1,2$. Assume that $\left(\delta_{i}^{\mathrm{c}_{k}}, \delta_{j}^{\mathrm{c}_{k}}\right)$ is an equilibrium point. Then, $\delta_{j}^{\mathrm{c}_{k}} \in \mathrm{BR}_{j}\left(\delta_{i}^{c_{k}}\right)$ where $\mathrm{BR}_{j}\left(\delta_{i}^{c_{k}}\right)=\left[\ell_{j}\left(\delta_{i}\right), 1\right]$. Since the game is symmetric, it must be the case that $\delta_{i}^{\mathrm{c}_{k}} \in \mathrm{BR}_{i}\left(\delta_{j}^{c_{k}}\right)$ where $\mathrm{BR}_{i}\left(\delta_{j}^{c_{k}}\right)=\left[\ell_{i}^{-1}\left(\delta_{i}\right), 1\right]$. Now, observe that $\mathrm{BR}_{i}\left(\delta_{j}^{c_{k}}\right) \cap \mathrm{BR}_{j}\left(\delta_{i}^{c_{k}}\right)=\emptyset$ since these two sets lie on opposite sides of the $45^{\circ}$ line. We conclude that $\left(\delta_{i}^{c_{k}}, \delta_{j}^{c_{k}}\right)$ are not mutual best-responses. To complete the proof, observe that the same holds for any point $\left(\delta_{i}^{\mathfrak{c}_{k}}, \delta_{j}^{\mathfrak{c}_{k}}\right)$ in $\operatorname{Region} \mathrm{II}_{(k)}, k=1,2$.

\section{B Proof of Proposition 3}

The idea of the proof is illustrated in Figure 4. Consider any $\delta_{j} \in[\tilde{\delta}, 1]$. Then, $\delta_{i}$ is a best-

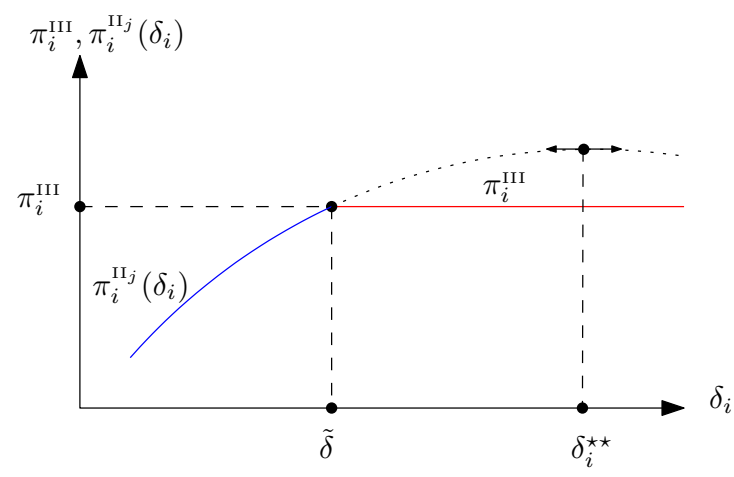

Fig. 4: The idea behind Proposition 3

reply to $\delta_{j}$ if $\pi_{i}^{\mathrm{III}} \geq \pi_{i}^{\mathrm{II}(j)}\left(\delta_{i}\right)$. Observe that Firm $i$ 's profit function is continuous in $\tilde{\delta}$. Indeed, 
we have: $\lim _{\delta_{i} \rightarrow \tilde{\delta}} \pi_{i}^{\mathrm{II}(j)}\left(\delta_{i}\right)=\pi_{i}^{\mathrm{III}}(\tilde{\delta})$. Now, observe that Owner $i$ 's profit function is strictly concave since

$$
\frac{\partial^{2} \pi_{i}^{\mathrm{II}}\left(\delta_{i j}\right)}{\partial \delta_{i}^{2}}=-\frac{r^{2}\left(9 b^{3}+16 b^{2} k+10 b k^{2}+2 k^{3}\right)}{b k(3 b+2 k)^{2}}<0 .
$$

and reaches a maximum for

$$
\delta_{i}^{\star \star}=\frac{(b+k)(r(3 b+k)(3 b+2 k)-a b k)}{t\left(9 b^{3}+16 b^{2} k+10 b k^{2}+2 k^{3}\right)} .
$$

Hence, $\pi_{i}^{\mathrm{III}} \geq \pi_{i}^{\mathrm{II}_{(j)}}\left(\delta_{i}\right)$ if $\delta_{i}^{\star \star} \geq \tilde{\delta}$ or, equivalently, if

$$
\delta_{i}^{\star \star}-\tilde{\delta}=-\frac{(3 b+2 k)\left(a k(2 b+k)^{2}-r(b+k)(3 b+k)^{2}\right)}{t(3 b+k)\left(9 b^{3}+16 b^{2} k+10 b k^{2}+2 k^{3}\right)} \geq 0 .
$$

The proof is completed by noting that Condition (31) holds provided that $r \geq r_{4}$. 


\section{CEE-M Working Papers 1 - 2019}

WP 2019 - 01

WP $2019-02$

WP 2019 - 03

WP $2019-04$

WP $2019-05$

WP 2019 - 06

WP $2019-07$

WP $2019-08$

WP $2019-09$

WP 2019 - 10

WP $2019-11$

WP $2019-12$
Adrien Nguyen-Huu. \& Antonin Pottier «Hicksian Traverse Revisited: Conditions for the Energy Transition»

Oumar Mbodji, Adrien Nguyen-Huu \& Traian A. Pirvu «Optimal Sharing Rule for a Household with a Portfolio Management Problem»

Tristan Cotty, Tristan, Elodie Maitre d'Hotel \&Julie Subervie «Inventory credit to enhance food security in Africa»

Raphael Soubeyran

«Incentives, Pro-social Preferences and Discrimination»

Adrien Fabre, Mouez Fodhaz \& Francesco Ricci «0ptimal Timing of Energy Production»

Claude Bismut \& Ismaël Rmajo

«A world of low interest rates»

Gabriela Demarchi, Julie Subervie, Fernando Palha Leite $\&$ Jean-Paul Laclau

« Farmers' preferences for water-saving strategies in brazilian eucalypt plantation »

Arnaud Tognetti, David Doat, Dimitri Dubois \& Rustam Romaniuc "Does the presence of a physically disabled erson in the group increase cooperation? An experimental test of the empathyaltruism hypothesis »

Isabelle Tritsch, Gwenole Le Velly, Benoit Mertens, Patrick, Meyfroidt, Christophe Sannier, Jean-Sylvestre Makak \& Kenneth Houngbedji « Do Forest-Management Plans and FSC Certification Reduce deforestation in the Congo Basin? »

Jean-Michel Salles

«Valuing the loss and damage from climate change: a review of some current issues »

Can Askan Mavi

«Can harmful events be another source of environmental traps? »

Daniel Serra

« Neuroeconomics and Modern Neuroscience »

\footnotetext{
${ }^{1}$ CEE-M Working Papers / Contact : laurent.garnier@inra.fr

- RePEc https://ideas.repec.org/s/hal/wpceem.html

- HAL https://halshs.archives-ouvertes.fr/CEE-M-WP/
} 
WP $2019-13$

WP 2019 - 14

WP $2019-15$

WP $2019-16$

WP $2019-17$

WP $2019-18$

WP $2019-19$

WP $2019-20$

WP $2019-21$

\section{Daniel Serra}

«La neuroeconomie en question : debats et controversies»

Claire Richert, Katrin Erdlenbruch \& Frédéric Grelot

« The impact of flood management policies individual adaptation actions:

insights from a French case study »

Margaux Lapierre, Alexandre Sauquet \& Julie Subervie

« Improving Farm Environmental Performance through Technical Assistance:

Empirical Evidence on Pesticide Use»

Pierre Levasseur, Katrin Erdlenbruch \& Christelle Gramaglia

«Why do people continue to live near polluted sites? Empirical evidence

from Southwestern Europe

Murielle Djiguemde, Dimitri Dubois, Alexandre Sauquet $\&$ Mabel Tidball

« On the modelling and testing of groundwater resource models»

Guillaume Cheikbossian

« Evolutionarily stable in-group altruism in intergroup Conflict »

Raphael Soubeyran

«Technology Adoption and Pro-social Preferences »

Marion Davin, Mouez Fodha \& Thomas Seegmuller

«Pollution in a globalized world: Are debt transfers among countries a solution? »

Denis Claude \& Mabel Tidball

«A new rationale for not picking low hanging fruits: The separation of ownership and control» 